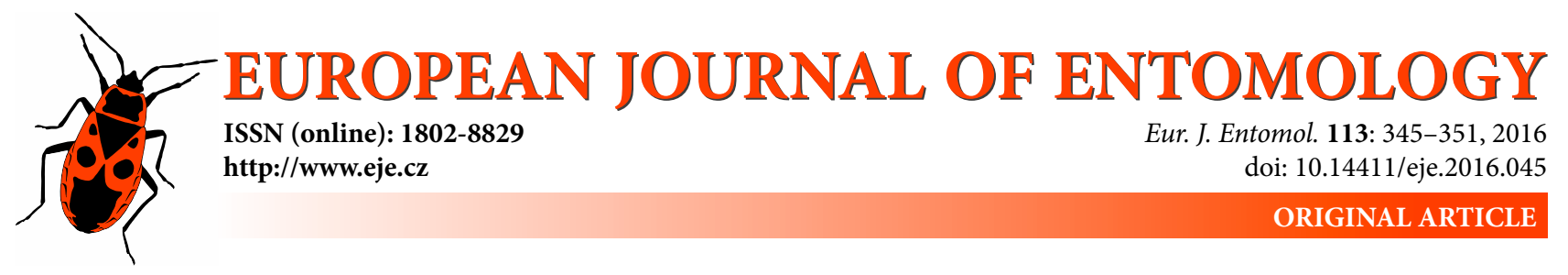

\title{
Partial consumption of different species of aphid prey by the predator Macrolophus pygmaeus (Hemiptera: Miridae)
}

\author{
DionYsSIOs LYKOURESSIS, DIONYSSIOS PERDIKIS* and loANNIS MANDARAKAS
}

Laboratory of Agricultural Zoology and Entomology, Agricultural University of Athens, lera Odos 75, 11855 Athens, Greece; e-mails: lykouressis@aua.gr, dperdikis@aua.gr

Key words. Heteroptera, Miridae, Macrolophus pygmaeus, Sternorrhyncha, Aphididae, Aphis gossypii, Macrosiphum euphorbiae, Myzus persicae, predation, biological control, superfluous killing, wasteful killing

Abstract. The partial consumption of prey refers to when a predator does not consume all the digestible biomass of an animal it has killed. The frequency of partial consumption of prey by the polyphagous predator Macrolophus pygmaeus (Hemiptera: Miridae) was recorded for different species of prey and prey population structures, in single and mixed prey species patches. All the instars of the aphid, Aphis gossypii, were provided as prey alone or together with Myzus persicae or Macrosiphum euphorbiae. Numbers killed were determined when equal (10 nymphs of each instar, 40 in total) or unequal numbers (higher numbers of young nymphs but again 40 in total) of nymphs were placed on an eggplant leaf in a plastic Petri dish. In each dish a single $5^{\text {th }}$ instar nymph of the predator was introduced and the numbers killed and numbers of partially consumed aphids were recorded after $24 \mathrm{~h}$, at $25 \pm 1^{\circ} \mathrm{C}$. The numbers of $A$. gossypii killed were higher than those of the other species of prey used. The frequency of partially consumed prey was highest when $A$. gossypii was offered alone in equal numbers of each instar, followed by when $A$. gossypii was provided together with M. persicae in unequal numbers of instars $(23.6 \%$ and $11.2 \%$, of the total mortality, respectively). Killed but not consumed prey was also recorded, at frequencies that reached $10.7 \%$ of the total mortality when $A$. gossypii was provided alone in equal numbers of each instar. For $M$. persicae and $M$. euphorbiae, these percentages were significantly lower. The higher frequency of this behaviour when $A$. gossypii was the prey may be related to its lower nutritional quality for the predator. The effect of prey instar was not significant. These results indicate that in determining the numbers killed by a predator, partially consumed prey may make up a significant part of the total kill and thus should be taken into consideration.

\section{INTRODUCTION}

In predator-prey interactions prey capture most likely leads to the predator eating its prey. Predators, however, do not always consume all of the ingestible biomass of their prey. This behaviour is referred to as "partial prey consumption" (Ernsting \& van der Werf, 1988), "wasteful killing" (Johnson et al., 1975) or "superfluous killing" (Riechert \& Maupin, 1998).

Partial prey consumption is commonly recorded in predators (Hassel et al., 1976), e.g., in mantids (Holling, 1966), the dipteran predatory fly Aphidoletes aphidimyza Rondani (Uygun, 1971), damselflies (Johnson et al., 1975), antlion larvae (Lucas, 1985), hoverfly larvae Metasyrphus corollae (F.) (Diptera: Syrphidae) (Barlow \& Whittingham, 1986), aquatic heteropteran predators (Dudgeon, 1990), anthocorids (Campbell, 1977; Meyling et al., 2003), carabids (Lang \& Gsödl, 2003), predatory mites (Hoyt, 1970; Sandness \& McMurtry, 1970) and spiders (Reichert, 1974; Samu \& Biro, 1993).
Partial prey consumption has been attributed to the predator's level of hunger or satiation, which is thought to internally motivate predatory behaviour (Holling, 1966). According to the "gut limitation model", this behaviour may occur when the total biomass available exceeds the hunger level of the predator (Holling, 1966; Johnson et al., 1975). In support of this hypothesis are the results of experiments that indicate the frequency of partially consumed prey is positively associated with prey population density and structure (Hoyt, 1970; Sandness \& McMurtry, 1970; Barlow \& Whittingham, 1986; Dudgeon, 1990; Samu, 1993; Samu \& Biro, 1993; Lang \& Gsödl, 2003; Fantinou et al., 2008). However, this behaviour also occurs when prey are present in lower numbers than the satiation levels (Sih, 1980). Foraging theory predicts that natural selection will favour those predators that maximize their net energy gain when foraging for prey (Pyke et al., 1977). According to the marginal value theorem (Charnov, 1976; Stephens \& Krebs, 1986) a predator may decide to discard its prey during feeding if the returns are lower than searching for an-

\footnotetext{
* Corresponding author; e-mail: dperdikis@aua.gr
} 
other item of prey. Similarly, optimality models suggest a higher frequency of this behaviour when the prey provides a lower energy return than that expected from capturing another item of prey (Lucas \& Grafen, 1985). Thus, a predator might abandon a part of the prey because it is difficult to consume or contains too little energy. Then the predators search for new prey in order to increase their energy intake per unit time (Charnov, 1976; Sih, 1980; Kruse, 1983; Inoda \& Kamimura, 2014). In fact, a higher frequency of this behaviour is reported when predators feed on prey of low nutritional quality (Meyling et al., 2003). In addition, partial consumption of prey may result from a preference for feeding on particular parts of a prey, which result in a predator abandoning a part of its prey and searching for new prey (Inoda \& Kamimura, 2014).

Another factor that could influence this behaviour is prey size since small prey may provide too little energy and thus time constraints and energy costs could make the decision to abandon prey partially consumed advantageous (Elton, 1927 as reported in Owen-Smith \& Mills, 2008; Griffiths, 1975). On the other hand, large prey are thought to be preferred (Bell, 1990), but associated with large size is an increase in handling time, which lowers their profitability (Sabelis, 1992). In the case of heteropteran predators, size is not important in determining partial prey consumption since the initial insertion of the stylets reduces the aphid's defensive reactions and results in its death, even if it is later abandoned (Ekbom, 1981).

Mortality associated with partial consumption of prey may have a major effect on the ability of a predator to regulate a prey population. In biological control, partial consumption of prey is associated with a greater effect on the target prey population (Sunderland, 1999). Consequently, studies that only determine the numbers of prey killed and completely consumed do not provide sufficient information for an accurate assessment of a predator's regulatory effect on a prey population and its ability to exploit different patches of prey effectively.

The heteropteran predator Macrolophus pygmaeus (Rambur) is an important natural enemy of insect pests on vegetables, including the aphids Aphis gossypii Glover, Myzus persicae Sulzer and Macrosiphum euphorbiae (Thomas). All these species cause severe damage to eggplant crops and are also resistant to insecticides (Koo et al., 2014; Voudouris et al., 2016).

The potential of $M$. pygmaeus for abandoning partially consumed prey is mentioned but not quantified by Castañé et al. (2004). The frequency of this behaviour is documented for each of the nymphal instars of $M$. persicae at a range of different temperatures (Fantinou et al., 2008). However, in the field aphid prey occurs in patches of different species of prey and ratios of instars, which differ in prey size and prey nutritional quality. The frequency of partial prey consumption, however, has been recorded in relatively simple environments in which a single type of prey is offered to the predator (Uygun, 1971; Lang \& Gsödl, 2003). Meyling et al. (2003) record this behaviour when two species of prey are offered simultaneously but used individuals of similar size. Therefore, in order to achieve a better insight into the significance of this behaviour its incidence in more complex patches of prey is needed.

The current study aimed to investigate and quantify the contribution of partial prey consumption by the generalist predator M. pygmaeus to total prey mortality. The hypotheses tested were (a) Among prey species of variable nutritional quality for this predator the incidence of this behaviour will be higher for the less suitable prey and (b) If prey size has an important role then, among prey of different sizes but of the same quality (i.e. nymphal instars belonging to the same species) the incidence of this behaviour should be higher for small prey.

\section{MATERIAL AND METHODS}

Macrolophus pygmaeus culture was established from individuals (adults and nymphs) collected in a tomato field in the area of Boeotia, central Greece. It was kept on potted eggplants (cv. Bonica) infested with $M$. persicae, in wooden framed muslin covered cages $(80 \times 80 \times 70 \mathrm{~cm})$ in a glasshouse at an average temperature of $22.5 \pm 2.5^{\circ} \mathrm{C}$ (mean $\pm \mathrm{SD}$ ) and natural lighting. The culture was renewed periodically by adding individuals collected in the above mentioned area. Similarly, cultures of A. gossypii, M. persicae and M. euphorbiae were maintained on eggplants.

The number of aphids killed by M. pygmaeus was recorded in an experimental arena with different prey population structures, i.e., equal or unequal numbers of nymphs of each instar of $A$. gossypii offered together with those of either M. persicae or M. euphorbiae.

In the first series of experiments only A. gossypii was provided, either in equal numbers of nymphs of each instar, i.e. 10 nymphs each of $1^{\text {st }}, 2^{\text {nd }}, 3^{\text {rd }}$ or $4^{\text {th }}$ instar or unequal numbers of nymphs of each instar $\left(18,13,7\right.$ or 2 nymphs of each of $1^{\text {st }}, 2^{\text {nd }}, 3^{\text {rd }}$ or $4^{\text {th }}$ instar $)$. Unequal numbers of of each instar were used in order to simulate an increasing population in which young individuals are the most common (i.e. Lykouressis \& van Emden, 1983).

In the second series of experiments a mixture of different species of prey was provided. In this case, A. gossypii nymphs were offered in equal or in unequal numbers together with nymphs of $M$. persicae or M. euphorbiae. In the experiments with equal numbers of nymphs 10 nymphs per instar of each species were placed in the dish. In the experiments with unequal numbers of nymphs, 18, 11,8 or 3 nymphs of each instar of M. persicae and $19,11,7$ or 3 nymphs of each instar of $M$. euphorbiae, were used. In all cases the total number of prey items available of a single species of aphid was 40 . In arenas with a mixture of prey the total number of prey items was 80 .

The number of aphids killed by 2 day old $5^{\text {th }}$ instar nymphs of M. pygmaeus was determined. These nymphs developed from young ones transferred from the culture cages to caged eggplants infested with $M$. persicae. Each eggplant was covered with a plastic cylindrical cage (11 cm diameter, $30 \mathrm{~cm}$ high) with two openings (9 $\mathrm{cm} \times 9 \mathrm{~cm}$ ), which along with the top opening, were covered with fine muslin. In this way the predators were preconditioned to the experimental conditions for at least a week.

The experimental arenas were plastic Petri dishes $(9 \mathrm{~cm}$ in diameter, $1 \mathrm{~cm}$ high) with a hole ( $3 \mathrm{~cm}$ in diameter) in the lid covered with fine muslin, for ventilation. In each dish a leaf of eggplant (cv. Bonica) was placed on a layer of cotton moistened with water with its lower surface facing upwards. Aphids used as prey were gently placed on the leaf using a fine brush and left to settle for $1 \mathrm{~h}$. Then, a single nymph of the predator was placed in the dish. The dishes were kept under constant conditions of $25 \pm 1{ }^{\circ} \mathrm{C}, 65 \pm 5 \% \mathrm{RH}$, and a $16 \mathrm{~L}: 8 \mathrm{D}$ photoperiod. 


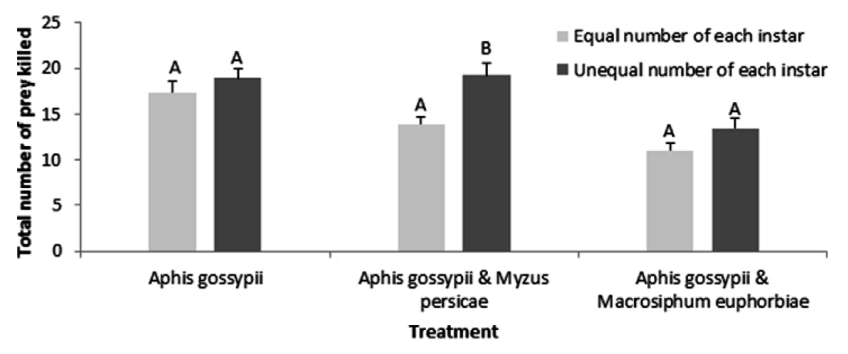

Fig. 1. Total number (mean \pm SE) of prey killed by a fifth instar nymph of Macrolophus pygmaeus foraging for $24 \mathrm{~h}$ in a Petri dish containing nymphs of Aphis gossypii, alone or together with nymphs of Myzus persicae or Macrosiphum euphorbiae in equal or unequal numbers of each instar. In these experiments 10 nymphs of each of the four nymphal instars were used; in the experiments with unequal numbers of nymphs 18,13, 7 or 2 nymphs of the 1st, 2 nd, 3rd or 4th instar of $A$. gossypii, 18, 11, 8 or 3 nymphs of each instar of $M$. persicae and 19, 11, 7 or 3 nymphs of each instar of $M$. euphorbiae, were provided. There were 25 replicates of each treatment. Means followed by the same capital letter in each treatment are not significantly different $(a=0.05$, Tukey HSD test).

The total number of aphids killed was counted $24 \mathrm{~h}$ after the predator was placed in the dish. In addition to the fully consumed prey, among the dead aphids there were also some dead aphids that were partially consumed or showing little signs of consumption (almost intact, with less than 1/10 of their body consumed). In defining partially consumed prey we followed the suggestion of Samu \& Biro (1993) who propose that partial prey consumption occurred when less than $1 / 3$ of the prey item was consumed. The killed aphids were placed in one of two separate categories: "partially consumed" or "killed but unconsumed". The latter were recognized by the slight change in the shape of their body due to feeding by the predator and also by a slight change in colour (darker) and the presence of a drop of exudate on the siphunculi, which indicates a predator attack (Nault et al., 1973). In fact, the aphids died after a predator inserted its stylets even if abandoned, as is recorded for the related predator Anthocoris nemorum L. (Hemiptera: Anthocoridae) (Ekbom, 1981). Each treatment was replicated 25 times.

The aphid mortality due to handling was determined in control experiments and found to be negligible (1\%) and was not considered further in the analysis of the data.

Data on the number of $A$. gossypii killed when provided alone in equal or unequal numbers (40 prey nymphs in the arena) and with $M$. persicae or $M$. euphorbiae in equal and unequal numbers were compared using 1-way ANOVA. Numbers killed of the different instars when $A$. gossypii was offered alone in equal numbers were compared using 1-way ANOVA, but the data were square-root transformed before the analysis. The percentage of the total number of prey killed that was partially consumed or killed but unconsumed was calculated for each replicate (predator individual). The data for $A$. gossypii when used alone in equal or unequal numbers were analyzed using 1-way ANOVA. The data obtained for arenas with a mixture of prey were analyzed using a two-way ANOVA with the factors: "treatment, A. gossypii with M. persicae or A. gossypii with M. euphorbiae" and "prey population structure, equal or unequal numbers of each instar". The percentages of each species of prey in each combination of different species of prey were compared using 1-way ANOVA. The data were arcsine transformed prior to the analyses to achieve normality.

In all cases, means were compared using the Tukey-Kramer (HSD) test $(\mathrm{a}=0.05)$. Analyses were done using the statistical package JMP (version 10, S.A.S Institute Inc., 2012).

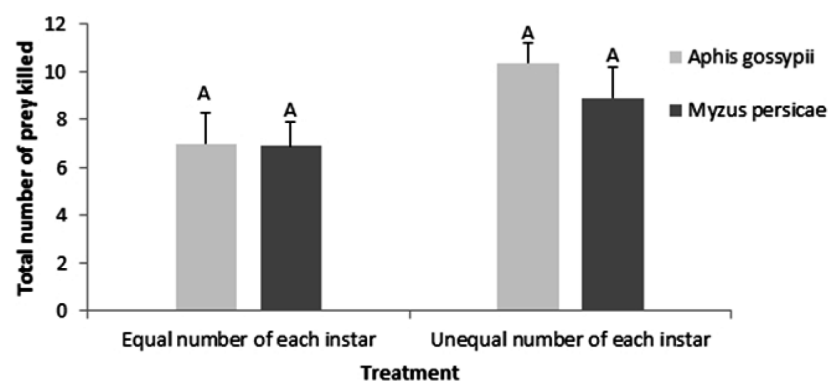

Fig. 2. Number (mean $\pm \mathrm{SE}$ ) of Aphis gossypii and Myzus persicae killed by a fifth instar nymph of Macrolophus pygmaeus foraging for $24 \mathrm{~h}$ in a Petri dish containing nymphs of $A$. gossypii and $M$. persicae in equal (10 nymphs of each instar, 40 in total for each aphid species) or unequal numbers of nymphs of each instar (18, 13,7 or 2 nymphs each of the $1^{\text {st }}, 2^{\text {nd }}, 3^{\text {rd }}$ or $4^{\text {th }}$ instar of $A$. gossypii, $18,11,8$ or 3 nymphs of each instar of $M$. persicae). There were 25 replicates of each treatment. Means followed by the same capital letter in each treatment are not significantly different $(a=0.05$, Tukey HSD test).

\section{RESULTS}

\section{Number of aphids killed}

The total number of $A$. gossypii killed was similar when provided alone either in equal or unequal numbers of instars $\left(\mathrm{F}_{1,48}=1.02, \mathrm{P}>0.31\right)$ (Fig. 1). The number of $A$. gossypii killed when equal numbers of each instar were offered alone was not significantly dependent on the instar $\left(\mathrm{F}_{3,96}=1.84, \mathrm{P}\right.$ $>0.14)$.

A significantly higher number were killed when $A$. gossypii was provided together with $M$. persicae in unequal than in equal numbers $\left(\mathrm{F}_{1,48}=12.48, \mathrm{P}<0.001\right)$ but was similar when provided together with $M$. euphorbiae $\left(\mathrm{F}_{1,48}=\right.$ 2.83, $\mathrm{P}>0.09$ ) (Fig. 1).

The total number of $A$. gossypii killed was similar to that of $M$. persicae when provided together in equal or unequal numbers $\left(\mathrm{F}_{1,48}=0.024, \mathrm{P}>0.87\right.$ and $\left.\mathrm{F}_{1,48}=1.74, \mathrm{P}>0.19\right)$ (Fig. 2), but was significantly higher than the number of $M$. euphorbiae killed $\left(\mathrm{F}_{1,48}=20.78, \mathrm{P}<0.01\right.$ and $\mathrm{F}_{1,48}=16.67$, $\mathrm{P}<0.01$, respectively) (Fig. 3).

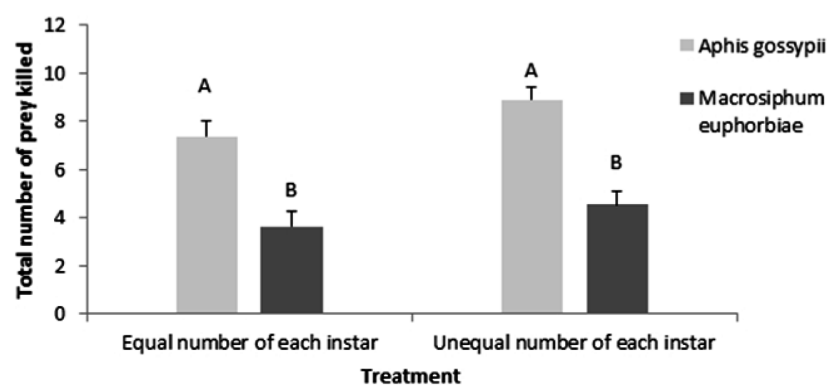

Fig. 3. Number (mean $\pm \mathrm{SE}$ ) of Aphis gossypii and Macrosiphum euphorbiae killed by a fifth instar nymph of Macrolophus pygmaeus foraging for $24 \mathrm{~h}$ in a Petri dish containing nymphs of $A$. gossypii and $M$. euphorbiae in equal (10 nymphs of each instar, 40 in total for each species) or unequal numbers of nymphs of each instar $\left(18,13,7\right.$ or 2 nymphs of $1^{\text {st }}, 2^{\text {nd }}, 3^{\text {rd }}$ or $4^{\text {th }}$ instar $A$. gossypii and $19,11,7$ or 3 nymphs of each instar of $M$. euphorbiae. There were 25 replicates of each treatment. Means followed by the same capital letter in each treatment are not significantly different $(a=0.05$, Tukey HSD test). 
Table 1. Percentage (mean \pm SE) of prey killed and partially consumed when a fifth instar nymph of Macrolophus pygmaeus foraged for $24 \mathrm{~h}$ in a Petri dish containing: (a) Only nymphs of Aphis gossypii (Ag) or (b) a mixture of aphids: A. gossypii together with nymphs of Myzus persicae (Mp) or Macrosiphum euphorbiae (Me). Nymphs were provided in equal or unequal numbers of each instar Values followed by a different letter in each treatment are significantly different.

\begin{tabular}{lcc}
\hline \multirow{2}{*}{ Treatment/Species } & \multicolumn{2}{c}{ Number of nymphs of each instar } \\
\cline { 2 - 3 } Aphis gossypii & $23.6 \pm 3.6 \mathrm{~A}$ & Unequal \\
$\mathrm{Ag}$ & & $9.5 \pm 1.4 \mathrm{~B}$ \\
Mixed species of prey - based on the total & number killed \\
$\mathrm{Ag}+\mathrm{Mp}$ & $8.2 \pm 2.3 \mathrm{AB}$ & $11.2 \pm 1.9 \mathrm{~A}$ \\
$\mathrm{Ag}+\mathrm{Me}$ & $7.5 \pm 1.3 \mathrm{AB}$ & $4.0 \pm 0.8 \mathrm{~B}$ \\
Mixed species of prey - based on the number of each species \\
of prey killed & & \\
$\mathrm{Ag}(+\mathrm{Mp})$ & $13.4 \pm 2.8 \mathrm{~A}$ & $18.0 \pm 3.0 \mathrm{~A}$ \\
$\mathrm{Mp}(+\mathrm{Ag})$ & $3.4 \pm 2.2 \mathrm{BC}$ & $3.2 \pm 1.2 \mathrm{BC}$ \\
$\mathrm{Ag}(+\mathrm{Me})$ & $10.5 \pm 2.7 \mathrm{AB}$ & $8.2 \pm 2.4 \mathrm{ABC}$ \\
$\mathrm{Me}(+\mathrm{Ag})$ & $3.0 \pm 1.7 \mathrm{BC}$ & $2.4 \pm 1.8 \mathrm{C}$ \\
\hline
\end{tabular}

\section{Number of aphids partially consumed}

When $A$. gossypii alone was the prey, the incidence of partially consumed prey expressed as a percentage of total mortality was significantly higher when each instar of this prey was provided in equal than in unequal numbers $\left(\mathrm{F}_{1,48}=\right.$ 10.08, $\mathrm{P}<0.003$ ) (Table 1).

The instar of the prey did not significantly affect the percentage of partially consumed prey when 10 nymphs of each instar of $A$. gossypii were individually provided $\left(\mathrm{F}_{3,96}\right.$ $=0.774, \mathrm{P}>0.512$ ).

The interaction between "treatment, $A$. gossypii with $M$. persicae or A. gossypii with M. euphorbiae" and "prey population structure, equal or unequal numbers of prey" in terms of the percentages of partially consumed prey was significant, whereas the effects of treatment and prey population structure were insignificant $\left(\mathrm{F}_{1,96}=4.32, \mathrm{P}<0.046\right.$ and $\mathrm{F}_{1,96}$ $=5.869, \mathrm{P}>0.076, \mathrm{~F}_{1,96}=0.272, \mathrm{P}>0.869$, respectively) The percentages of the prey recorded partially consumed were highest in the treatment $A$. gossypii $+M$. persicae in unequal or equal numbers of instars and lowest when $A$. gossypii was provided together with $M$. euphorbiae (Table $1)$.

The percentages of the different species of prey in the different treatments that were partially-consumed, when provided together, were significantly different $\left(\mathrm{F}_{7,192}=7.70, \mathrm{P}<\right.$ 0.001 ) (Table 1). The percentages of the prey partially-consumed were highest for $A$. gossypii when provided together with $M$. persicae in unequal or equal numbers of instars. For M. persicae and M. euphorbiae these percentages were much lower.

\section{Killed but unconsumed prey}

When only A. gossypii was provided as prey in equal or unequal numbers, the numbers killed but not consumed were not significant $\left(\mathrm{F}_{1,48}=0.045, \mathrm{P}>0.83\right)$.

The influence of the prey instar on the percentage of prey killed but not consumed was not significant when 10 nymphs
Table 2. Percentages (mean \pm SE) of prey killed and unconsumed when a fifth instar nymph of Macrolophus pygmaeus foraged for $24 \mathrm{~h}$ in a Petri dish containing: (a) Only nymphs of Aphis gossypii $(\mathrm{Ag})$ or (b) a mixture of aphids: $A$. gossypii together with nymphs of Myzus persicae (Mp) or Macrosiphum euphorbiae (Me). Nymphs were offered in equal or unequal numbers of each instar. Values followed by a different letter in each treatment are significantly different.

\begin{tabular}{|c|c|c|}
\hline \multirow{2}{*}{ Treatment/Species } & \multicolumn{2}{|c|}{ Number of nymphs of each instar } \\
\hline & Equal & Unequal \\
\hline \multicolumn{3}{|l|}{ Aphis gossypii } \\
\hline $\mathrm{Ag}$ & $10.7 \pm 2.7 \mathrm{~A}$ & $8.9 \pm 1.7 \mathrm{~A}$ \\
\hline \multicolumn{3}{|c|}{ Mixed prey species - total rates } \\
\hline $\mathrm{Ag}+\mathrm{Mp}$ & $3.1 \pm 1.0 \mathrm{~B}$ & $8.6 \pm 1.4 \mathrm{~A}$ \\
\hline $\mathrm{Ag}+\mathrm{Me}$ & $5.0 \pm 1.3 \mathrm{AB}$ & $2.5 \pm 0.1 \mathrm{~B}$ \\
\hline \multicolumn{3}{|c|}{ Mixed prey species - rates per prey species } \\
\hline $\mathrm{Ag}(+\mathrm{Mp})$ & $3.9 \pm 1.6 \mathrm{BC}$ & $10.4 \pm 1.9 \mathrm{~A}$ \\
\hline $\mathrm{Mp}(+\mathrm{Ag})$ & $1.3 \pm 1.1 \mathrm{C}$ & $5.6 \pm 1.7 \mathrm{ABC}$ \\
\hline $\mathrm{Ag}(+\mathrm{Me})$ & $8.6 \pm 2.7 \mathrm{AB}$ & $4.1 \pm 1.5 \mathrm{BC}$ \\
\hline $\mathrm{Me}(+\mathrm{Ag})$ & $0.0 \pm 0.0 \mathrm{C}$ & $1.7 \pm 1.2 \mathrm{BC}$ \\
\hline
\end{tabular}

of each instar of $A$. gossypii were provided $\left(\mathrm{F}_{3,96}=1.779, \mathrm{P}\right.$ $>0.156$, respectively).

In the case of the number of prey killed but not consumed there was a significant interaction between the "treatment, A. gossypii with $M$. persicae or A. gossypii with M. euphorbiae" and "prey population structure, equal or unequal numbers" $\left(\mathrm{F}_{1,96}=11.71, \mathrm{P}<0.001\right)$, but the effects of the main factors were insignificant $\left(\mathrm{F}_{1,96}=3.71, \mathrm{P}>0.069\right.$ and $\mathrm{F}_{1,96}=2.91, \mathrm{P}>0.09$ for the treatment and prey population structure effect, respectively) (Table 2). Generally, percentages were higher in the treatment $A$. gossypii with $M$. persicae in unequal numbers of instars followed by $A$. gossypii with $M$. euphorbiae in equal numbers.

The percentages of the different species of prey killed but not consumed when provided together, differed significantly $\left(\mathrm{F}_{7,192}=6.22, \mathrm{P}<0.001\right)$ (Table 2). These percentages were higher for $A$. gossypii when provided in unequal numbers with $M$. persicae or in equal numbers with $M$. euphorbiae. The percentages recorded when $M$. persicae was provided were lower and much lower when M. euphorbiae was provided.

\section{DISCUSSION}

The present study revealed that the frequencies with which $M$. pygmaeus partially consumed or killed but did not consume prey were highest when $A$. gossypii was provided alone in equal numbers of each instar, with a cumulative average of $34.3 \%$ of the total number of prey killed. Percentages of $A$. gossypii killed were also high when provided together with $M$. persicae or $M$. euphorbiae. However, the effect of instar was not significant. Although, it remains to be determined whether the same behaviour occurs at similar levels when M. pygmaeus forages under field conditions in which it can switch to another prey patch, our results provide support for the idea that partial prey consumption is important in determining a predator's ability to suppress populations of $A$. gossypii.

Partial prey consumption amounts to $15.4 \%$ and $7.6 \%$ of the total prey killed by the predatory bugs Anthocoris 
nemoralis (Fabricius) and A. nemorum (Hemiptera: Anthocoridae) when foraging in arenas where both $M$. persicae and Aulacorthum solani (Kaltenbach) are present. However, a substantial increase in the percentage of partially consumed prey occured when 30 fourth instar $M$. persicae and 30 third instar $A$. fabae were provided as prey, with $90.3 \%$ or $56.7 \%$ of the $A$. fabae individuals killed only partially consumed by each species of anthocorid, respectively (Meyling et al., 2003). The carabid Poecilus cupreus (L.) partially consumes $43 \%$ of the aphid prey it kills, when foraging in an arena in which there are 20 Rhopalosiphum padi (L.) (Hemiptera: Aphididae) (Lang \& Gsödl, 2003). Larvae of $A$. aphidimyza partially consume most of the aphids they kill (Uygun, 1971). The above results and those of the current study highlight the fact that the number of prey partially consumed may constitute a relatively high proportion of the mortality caused by an insect predator and thus should not be ignored when evaluating predation rates.

The numbers of $M$. persicae and $M$. euphorbiae partially consumed by $M$. pygmaeus in this study were much lower than those recorded when exploiting $A$. gossypii. The rates of partial consumption of each instar of $M$. persicae are reported by Fantinou et al. (2008). In that study the percentage of unconsumed prey was generally low, being $19 \%$ and $17 \%$ when 20 or 24 fourth instar nymphs were provided, respectively.

Generally, prey selection decisions are based on balancing the energetic value of the prey with the handling time and search time (Krebs \& Davies, 1993). The influence of prey size on searching is reflected in the fact that small prey may be partially consumed because of the small amount of energy they provide (Elton, 1927 as reported by OwenSmith \& Mills, 2008; Griffiths, 1975). Aphis gossypii was the smallest species of prey used in this study. However, prey size did not significantly affect the frequency of partially consumed prey when 10 nymphs of each instar of $A$. gossypii were provided. Prey size also did not have a significant affect when patches containing a mixture prey species of a more diverse range of sizes were used. However, the structure of a prey patch is an important factor in determining the frequency of partial prey consumption. It was significantly higher when $A$. gossypii was offered alone in equal numbers than in unequal numbers and in the 2-prey treatments, when $A$. gossypii and $M$. persicae were offered in unequal numbers. These results indicate that there may be interactions between different species of prey and prey population structure, which need further evaluation.

The different frequency of this behaviour record for the different species of prey studied may also be associated with their different nutritional quality for the predator. Tedeschi et al. (1999) report that young nymphs of M. pygmaeus fail to complete their development even though they consume an average 14.8 young nymphs of $A$. gossypii per day. In fact, $A$. gossypii is an inferior food source not only for development but more so for reproduction of $M$. pygmaeus, compared to M. persicae and M. euphorbiae (Perdikis \& Lykouressis, 2000, 2002, 2003). Similar results on the suitability of $A$. gossypii and $M$. persicae are reported by Fauvel et al. (1987). Thus, the lower nutritional quality of $A$. gossypii can account for the high levels of partial consumption. Similar results are reported for the generalist predators, $P$. cupreus and $A$. nemoralis, feeding on $R$. padi and A. fabae (Lang \& Gsödl, 2003; Meyling et al., 2003, respectively).

In this study, the effect of satiation on the frequency of this behaviour is not due to gut limitation (Holling, 1966; Johnson et al., 1975) since the total biomass of prey available to the predator was similar in all the treatments.

Although partial prey consumption is reported for several species of predator, the reasons for killing and then abandoning unconsumed prey has been little studied. In the case of $A$. aphidimyza the killed and unconsumed prey can make up as high as $50 \%$ of the prey killed. Generally, in $A$. aphidimyza this behaviour is much more frequent than killing and partially consuming prey (Uygun, 1971). However, for $M$. pygmaeus, the frequency of killed and unconsumed prey was similar or lower than that of killed and partially consumed prey. This difference between M. pygmaeus and A. aphidimyza could be related to differences in their behaviour.

The relatively high percentage of killed and unconsumed prey indicates that $M$. pygmaeus tastes the prey to decide whether to continue consuming or to reject it. In fact, sucking predators can abandon prey after initial testing or at any time during the feeding process (Pollard, 1988). Thus, $M$. pygmaeus may receive information when it starts feeding on the victim, which is crucial for its decision to continue consuming the prey or to abandon it. The taste of aphid prey or possible deterrents in the haemolymph of the prey are thought to be a major factor in the predators' decision to leave it unconsumed in the case of predatory bugs (Meyling et al., 2003).

The current study provides evidence of the potential of $M$. pygmaeus for reducing populations of $A$. gossypii. In fact, as A. gossypii is smaller than M. persicae and M. euphorbiae the expectation is that predators will kill more of them. The numbers of different instars of $A$. gossypii killed when provided alone was higher than the numbers of $M$. persicae or M. euphorbiae reported killed in the study of Lykouressis et al. (2007) i.e. 9.22 and 5.28 aphids for M. persicae and $M$. euphorbiae, respectively, when equal numbers of each instar were provided. Thus, from an applied point of view, this predator would appear to be a good biocontrol agent for reducing the numbers of $A$. gossypii on eggplant.

In conclusion, partial prey consumption is a significant part of the total prey mortality inflicted by the predator $M$. pygmaeus. The incidence of this behaviour was associated with the species of prey and the ratios of different types of prey in a patch. It was more frequent when the prey were of a low nutritional quality, but the effect of prey size was insignificant. The behaviour of killing but abandoning prey unconsumed is an important aspect of predatory behaviour and should not be ignored. This data can be useful in further studies aimed at investigating prey selection decisions 
of predatory bugs but also their suppressing effect on prey populations.

\section{REFERENCES}

Barlow C.A. \& Whittingham J.A. 1986: Feeding economy of larvae of a flower fly, Metasyrphus corollae (Dip.: Syrphidae): partial consumption of prey. - Entomophaga 31: 49-57.

BeLl W.J. 1990: Searching Behaviour - The Behavioural Ecology of Finding Resources. Chapman \& Hall, London, $358 \mathrm{pp}$.

CAMPBell C.A.M. 1977: A laboratory evaluation of Anthocoris nemorum and A. nemoralis (Hem. Anthocoridae) as predators of Phorodon humuli (Hom.: Aphididae). - Entomophaga 22: 309-314.

Castañé C., Alomar O., Goula M. \& Gabarra R. 2004: Colonization of tomato greenhouses by the predatory mirid bugs Macrolophus caliginosus and Dicyphus tamaninii. - Biol. Contr. 30: 591-597.

Charnov E.L. 1976: Optimal foraging, the marginal value theorem. - Theor. Popul. Biol. 9: 129-136.

Dudgeon D. 1990: Feeding by the aquatic heteropteran, Diplonychus rusticum (Belostomatidae): an effect of prey population structure on meal size. - Hydrobiologia 190: 93-96.

Еквом B.S. 1981: Efficiency of the predator Anthocoris nemorum (Het.: Anthocoridae) against the greenhouse whitefly, Trialeurodes vaporariorum (Hom.: Aleyrodidae). - J. Appl. Entomol. 92: 26-34.

ERNSTING G. \& VAN DER WERF D.C. 1988: Hunger, partial consumption of prey and prey size preference in a carabid beetle. - Ecol. Entomol. 13: 155-164.

Fantinou A.A., Perdikis D.Ch., Maselou D.A. \& Lambropoulos P.D. 2008: Prey killing without consumption: does Macrolophus pygmaeus show adaptive foraging behavior? - Biol. Contr. 47: 187-193.

Fauvel G., Malausa J.C. \& Kaspar B. 1987: Etude en laboratoire des principales charactéristiques biologiques de Macrolophus caliginosus (Heteroptera: Miridae). — Entomophaga 32 529-543.

GRIFFITHS D. 1975: Prey availability and the food of predators. Ecology 56: 1209-1214.

Hassell M.P., Lawton J.H. \& Beddington J.R. 1976: The components of arthropod predation. I. The prey death rate. - J. Anim. Ecol. 45: 135-164.

HolLing C.S. 1966: The functional response of invertebrate predators to prey population structure. - Mem. Entomol. Soc. Can. 48: 1-86.

Hoyт S.C. 1970: Effect of short feeding periods by Metaseiulus occidentalis on fecundity and mortality of Tetranychus mcdanieli. — Ann. Entomol. Soc. Am. 63: 1382-1384.

Inoda T. \& Kamimura S. 2014: Choice of prey body parts for effective feeding by predaceous diving beetle larvae, Dytiscus sharpi sharpi (Wehncke) (Coleoptera: Dytiscidae). - J. Insect Behav. 28: 26-36.

Johnson D.M., AKre B.G. \& Crowley P.H. 1975: Modelling arthropod predation: wasteful killing by damselfly naiads. Ecology 56: 1081-1093.

Koo H.-N., An J.-J., PARK S.-E., Kim J.-I. \& KIM G.-H. 2014: Regional susceptibilities to 12 insecticides of melon and cotton aphid, Aphis gossypii (Hemiptera: Aphididae) and a point mutation associated with imidacloprid resistance. - Crop Prot. 55: 91-97.

Krebs J.R. \& Davies N.B. 1993: An Introduction to Behavioral Ecology. Blackwell Science, Oxford, 520 pp.

KRUSE K.C. 1983: Optimal foraging by predaceous diving beetle larvae on toad tadpoles. - Oecologia 58: 383- 388.
LANG A. \& GsöDL S. 2003: Superfluous killing of aphids: a potentially beneficial behaviour of the predator Poecilus cupreus (L.) (Coleoptera: Carabidae)? - J. Plant Dis. Prot. 110: 583-590.

LUCAS J.R. 1985: Partial prey consumption by antlion larvae. Anim. Behav. 33: 945-958.

LuCAS J.R. \& Grafen A. 1985: Partial prey consumption by ambush predators. - J. Theor. Biol. 113: 455-473.

LyKouRESSIS D.P. \& vAN EMDEN H.F. 1983: Factors affecting the potential increase rate (e $\lambda$, PIR), as defined by Hughes, in populations of Sitobion avenae (F.) (Hemiptera: Aphididae). - Entomol. Hellen. 1: 53-57.

Lykouressis D., Perdikis D. \& Gaspari M. 2007: Prey preference and biomass consumption by Macrolophus pygmaeus (Hemiptera: Miridae) on Myzus persicae and Macrosiphum euphorbiae (Hemiptera: Aphididae). - Eur. J. Entomol. 104: 199-204.

Meyling N., Enkegaard A. \& Brodsgandd H. 2003: Two Anthocoris bugs as predators of glasshouse aphids: voracity and prey preference. — Entomol. Exp. Appl. 108: 59-70.

Nault L.R., Edwards L.J. \& STYer W.E. 1973: Aphid alarm pheromones: secretion and reception. - Environ. Entomol. 2: 101-105.

Owen-Smith N. \& Mills M.G. 2008: Predator-prey size relationships in an African large-mammal food web. - J. Anim. Ecol. 77: 173-183.

Perdikis D. \& LyKouRessis D. 2000: Effects of various items, host plant and temperature on the development and survival of Macrolophus pygmaeus (Rambur) (Hemiptera: Miridae). — Biol. Contr. 17: 55-60.

Perdikis D.Ch. \& Lykouressis D.P. 2002: Life table and biological characteristics of Macrolophus pygmaeus when feeding on Myzus persicae and Trialeurodes vaporariorum. - Entomol. Exp. Appl. 102: 261-272.

Perdikis D.Ch. \& LyKouRessis D.P. 2003: Aphis gossypii as a factor inhibiting the survival and population increase of the predator Macrolophus pygmaeus on cucumber. - Eur. J. Entomol. 100: 501-508.

POLLARD S.D. 1988: Partial consumption of prey: the significance of prey water loss on estimates of biomass intake. - Oecologia 76: 475-476.

Pyke G.H., Pullian H.R. \& Charnov E.L. 1977: Optimal foraging: a selective review of theory and tests. - Quart. Rev. Biol. 52: 137-154.

REICHERT S.E. 1974: Thoughts on the ecological significance of spiders. - Bioscience 24: 352-356.

REICHERT S.E \& MAUPIN J.L. 1998: Spider effects on prey: tests for superfluous killing in five web-builders. In Selden P.A. (ed.): Proceedings of the 17th European Colloquium of Arachnology, Edinburgh, 1997. British Arachnological Society, Edinburgh, pp. 203-210.

SABelis M.W. 1992: Predatory arthropods. In Crawley M.J. (ed.): Natural Enemies. Blackwell Scientific, Oxford, pp. 225-264.

SAmu F. 1993: Wolf spider feeding strategies: Optimality of prey consumption in Pardosa hortensis. - Oecologia 94: 139-145.

SAMU F. \& BIro Z. 1993: Functional response, multiple feeding and wasteful killing in a wolf spider (Araneae: Lycosidae). Eur. J. Entomol. 90: 471-476.

SANDNESS J.N. \& MCMurtry J.A. 1970: Functional response of three species of Phytoseiidae (Acarina) to prey population structure. - Can. Entomol. 102: 692-704.

SAS INSTITUTE INC. 2009: $J M P \circledR 8$ User Guide. 2nd ed. SAS Institute Inc., Cary, NC.

Siн A. 1980: Optimal foraging: Partial consumption of prey. Am. Nat. 116: 281-290. 
StePhens D.W. \& Krebs J.R. 1986: Foraging Theory. Princeton University Press, Princeton, 247 pp.

SunderLand K.D. 1999: Mechanisms underlying the effects of spiders on pest control. - J. Arachnol. 27: 308-316.

Tedeschi R., De Clerce P., Van de Veire M. \& Tirry L. 1999: Development and predation of Macrolophus caliginosus (Heteroptera: Miridae) on different prey. - Med. Fac. Landbouwkd. Univ. Gent 64: 235-240.

Uygun N. 1971: Der Einfluss der Nahrungsmenge auf Fruchtbarkeit und Lebensdauer von Aphidoletes aphidimyza (Rond.) (Diptera: Itonididae). — J. Appl. Entomol. 69: 234-258.
Voudouris C.C., Kati A.N., Sadikoglou E., Williamson M., Skouras P., Dimotsiou O., Georgiou S., Fenton B., Skavdis G. \& Margaritopoulos J.T. 2013: Insecticide resistance status of Myzus persicae in Greece: long-term surveys and new diagnostics for resistance mechanisms. - Pest Manag. Sci. 72: 671-683.

Received September 1, 2015; revised and accepted March 23, 2016 Published online April 26, 2016 